\title{
Reproducibility of pulmonary function tests under laboratory and field conditions
}

\author{
R G LOVE, M D ATTFIELD,* AND K D ISLES $\dagger$ \\ From the Institute of Occupational Medicine, Edinburgh EH8 9SU, UK
}

ABSTRACT The reproducibility of pulmonary function tests in the laboratory and in a mobile field survey vehicle has been studied. Groups of laboratory workers were studied at base and a random sample of 38 coalminers was examined in the mobile laboratory. The intra-subject variability of some newer tests of lung function, including closing volume and maximum flow at low lung volumes, has been compared with that of well-established tests, such as lung volumes and forced expiratory volume from two measurements made more than one day apart. Most measurements were slightly less reproducible in the study of coalminers than in the laboratory personnel. Conventional tests, such as forced expiratory volume in one second, lung volumes, single breath $\mathrm{CO}$ transfer factor, and exercise ventilation were very reproducible, the coefficients of variation (cov) being generally between $5 \%$ and $10 \%$. The closing volume test, maximum expiratory flow at low lung volumes, and the single breath $\mathrm{N}_{2}$ index were less reproducible: cov between $15 \%$ and $39 \%$ in the miners. The forced expired time and volume of isoflow, measured only on laboratory workers, however, exhibited greater reproducibility than previously reported (cov $=10 \%$ and $15 \%$ respectively). It is suggested that, when assessing the repeatability of lung function tests, account should be taken of the circumstances in which the intra-subject variability was measured.

Pulmonary function tests, which are carried out on selected workers at the nine collieries that form the National Coal Board's Pneumoconiosis Field

\section{Present addresses:}

*Epidemiology Investigations Branch, ALOSH, 944 Chestnut Ridge Road, Morgantown, West Virginia 26505, USA.

+Department of Statistics and Economic Forecasting, Bank of Scotland, Edinburgh.

Received 27 November 1978

Accepted 21 February 1979
Research programme, have recently been extended to include tests considered to reflect changes in the function of small airways as a means of clarifying the known relationship ${ }^{1}$ between functional changes and occupational dust exposure in coalminers.

The present investigation reports the withinsubject variability of the main tests of lung function performed in these surveys. The reproducibility of conventional and newer tests of lung function conducted on subjects under typical laboratory conditions and on naive industrial workers under field conditions has been investigated.

Table 1 Number, age, and smoking habits of participants in laboratory and field trials

\begin{tabular}{|c|c|c|c|c|c|}
\hline \multirow[t]{2}{*}{ Test } & \multirow[t]{2}{*}{ No } & \multirow{2}{*}{$\begin{array}{l}\text { Age, years } \\
\text { Mean (range) }\end{array}$} & \multicolumn{3}{|c|}{ Smoking habit $\S$} \\
\hline & & & $S$ & $N$ & $X$ \\
\hline \multicolumn{6}{|c|}{ Lahoratory } \\
\hline $\begin{array}{l}\text { Static lung volumes and } \mathrm{TLCOSB}^{*} \\
\text { Forced expiration and closing volume } \\
\text { Exercise ventilation and TLCoss* } \\
\text { FET and V iso } \dot{V} \dagger\end{array}$ & $\begin{array}{l}40 \\
16 \\
36 \\
19\end{array}$ & $\begin{array}{l}37 \cdot 7(19-64) \\
32 \cdot 2(23-53) \\
33 \cdot 8(21-59) \\
30 \cdot 2(19-50)\end{array}$ & $\begin{array}{r}19 \\
3 \\
10 \\
7\end{array}$ & $\begin{array}{c}16 \\
11 \\
23 \\
9\end{array}$ & $\begin{array}{l}5 \\
2 \\
3 \\
3\end{array}$ \\
\hline \multicolumn{6}{|c|}{ Field } \\
\hline All tests except FET and $V$ iso $\dot{V}$ & $38+$ & $40 \cdot 2(18-61)$ & 22 & 6 & 7 \\
\hline
\end{tabular}

* Diffusing capacity for carbon monoxide during single breath and steady state.

$\dagger$ FET $=$ Forced expiratory time: $\mathbf{V}$ iso $\dot{\mathbf{V}}=$ Volume of isoflow .

†Includes three subjects whose smoking history was unknown.

$\S S=$ Smoker $;=$ Non-smoker; $X=$ Ex-smoker. 


\section{Methods}

Before the introduction of each pulmonary function test in our mobile survey unit, measurements of between-visit and, if necessary, within-visit variability were made in the laboratory over a three-year period. A trial was also held in the mobile laboratory used for field surveys, and all the tests then currently used in the survey were assessed for reproducibility on working coalminers at a local colliery.

Male staff employed at this institute volunteered to act as subjects in the laboratory trials. Table 1 details the numbers, age, and smoking habits of the men carrying out each series of tests. No one was rejected specifically because of the presence of respiratory symptoms. In all cases the subjects attended the laboratory on two separate occasions at about the same time of day and where possible on the same day of the following week, although in practice the intervals between tests on any subject varied from one day to several weeks, mainly due to the unavailability of the subjects. It appears, however, that within- and between-day variations are not significant for measurements derived from flowvolume and closing volume manoeuvres. ${ }^{2} 3$

For the field trial 40 working miners were randomly selected from five ten-year age groups, and this was the sole basis for selection. Two of these men failed to attend leaving 38 subjects for the trial (table 1). Each man attended the mobile laboratory at the same time of the same day of two successive weeks. Height, weight, and smoking habits were recorded at the time of the trials.

The following tests were carried out in separate trials in the laboratory but were performed at the same visit during the field trial.

\section{.LUNG VOLUMES AND SINGLE BREATH \\ TRANSFER FACTOR}

Lung volumes and single breath transfer factor (TLCOSB) were measured on an automated spirometer (Resparameter Mk 3, PK Morgan Ltd, Chatham, Kent). Vital capacity (VC), functional residual capacity (FRC) residual volume (RV), and total lung capacity (TLC) were determined once by helium dilution, and duplicate measurements of TLCO were made during breathholding ${ }^{4}$ and their mean calculated.

FORCED EXPIRATORY VOLUME AND MAXIMUM EXPIRATORY FLOW-VOLUME CURVES

Forced expiratory volumes and maximum expiratory flow-volume curves were recorded on an electronic waterless spirometer (Ohio Medical Products, Wisconsin-Model No 800). After one or two practice blows three forced expirations were traced as flow-volume (FV) curves on a fast response X-Y recorder (Hewlett-Packard, Model No 7045A), from which forced expiratory volume in one second $\left(F V_{1}\right)$, forced vital capacity (FVC), and maximum expiratory flow at $50 \%$ and $25 \%$ of forced vital capacity $\left(\dot{V} \max 50\right.$ and $\left.\dot{\mathrm{V}} \max _{25}\right)$ were measured. The mean values of these variables were calculated, if the FVCs were within $200 \mathrm{ml}$ of each other, by measuring $25 \%$ and $50 \% \mathrm{FVC}$ from RV. If an otherwise technically satisfactory FVC was more than $200 \mathrm{ml}$ but less than $10 \%$ below the highest FVC, Vmax 50 and $\dot{V m a x}_{25}$ were determined using the FVC of that particular FV curve.

A one-second timer, calibrated from 50 cycles/ second mains frequency, was activated by expulsion of the first $100 \mathrm{ml}$ of air and traced. via an event marker, a one-second interval on the volume axis of the $X-Y$ recordel, from which $F_{E V} V_{1}$ was read.

Forced expired time (FET), defined as the time taken to expel a vital capacity breath, was measured by means of a digital timer, which was activated by expulsion of the first $100 \mathrm{ml}$ of air and switched off when flow had fallen below about $50 \mathrm{ml} / \mathrm{s}$.

The subject was subsequently connected to a gas mixture containing $80 \% \mathrm{He} / 20 \% \mathrm{O}_{2}$, from which he took three near VC inspirations, At the end of the third inhalation he was instructed to exhale forcibly into the spirometer. Two, or more if necessary, flow-volume curves were recorded and the curve with the highest peak flow and FVC was used to compare expiratory flows for determination of the volume of isoflow ( $\mathrm{V}$ iso $\dot{\mathrm{V}}$ ) by the method of Hutcheon et al. ${ }^{5}$ If $\mathrm{FVC}$ on $\mathrm{He} / \mathrm{O}_{2}$ differed from FVC on air the relevant $\mathrm{He} / \mathrm{O}_{2}$ curve was superimposed with the best air curve for measurement of $\mathrm{V}$ iso $\dot{V}$. FET and $\mathrm{V}$ iso $\dot{\mathrm{V}}$ were not determined on the miners.

It was only possible to measure $\mathrm{FEV}_{1}$ on a modified Gaensler water-filled spirometer during the field study, so that each subject, allocated alternately, had to blow three times into one spirometer followed by three blows into the second spirometer to record $\dot{V}_{\max }{ }_{50}$ and $\dot{V} \max _{25}$.

Although the same timer was used in both studies, a small systematic difference between the spirometers led to the mean $F E V_{1}$ values from the Gaensler spirometer being slightly higher in the group of miners than if the Ohio spirometer had been used. This should not have affected the between visit variation of $F E V_{1}$, however, since such systematic effects have been allowed for in thc subsequent analysis.

CLOSING VOLUME AND THE SINGLE BREATH NITROGEN INDEX

Closing volume and the single breath nitrogen index 
were estimated by the single breath nitrogen method. ${ }^{6}$ The outputs from the $\mathrm{N}_{2}$ analyser (Ohio Medical Products, Wisconsin-Model No 700) and volume output from the spirometer (Ohio-Model No 800) were recorded on the X-Y recorder. It was possible to measure from this tracing the single breath $\mathrm{N}_{2}$ index between $750 \mathrm{ml}$ and $1250 \mathrm{ml}^{6}$ and closing volume (CV). ${ }^{7}$ Closing capacity (CC) was calculated using the previously measured $\mathrm{RV}$ and TLC. ${ }^{8}$

Inspiratory and expiratory flows were controlled by in-line resistances, designed to keep airflow below about $0.5 \mathrm{l} / \mathrm{min}$. At these low flow rates differences in response-times of the $\mathrm{N}_{2}$ meter and spirometer, if present, would not cause any significant distortion of the tracings. Any expirations that were clearly too rapid were rejected by the technician conducting the test.

The point of inflection was estimated according to the criteria suggested by the US National Heart and Lung Institute. ${ }^{9}$ Two observers read the traces independently. There were no consistent differences in the means and coefficients of variation determined by the observers but the values of only one observer (KS) are included in this analysis, since his readings were marginally more consistent.

\section{VENTILATORY RESPONSE TO EXERCISE}

The ventilatory response to exercise was measured by having the subjects pedal an electrically braked constant-load bicycle ergometer (Elema-Schonander, Stockholm) at successive five-minute loads of 50 , 75,100 , and 125 watts at 60 revolutions a minute. The subject inspired a gas mixture of $0.05 \%$ carbon monoxide in air and the inspiratory minute volume $\dot{\mathrm{V}}_{1}$, was measured on a Parkinson-Cowan dry gas meter. Expired air was collected during the fourth and fifth minutes of each exercise period for analysis of $\mathrm{FEO}_{2}$ and $\mathrm{FECO}$, from which $\mathrm{no}_{2}\left(\mathrm{O}_{2}\right.$ consumption in $\mathrm{mmol} / \mathrm{min}$ ) and steady state transfer factor, TLcoss, were respectively derived. The latter was calculated by method 1 (assumed dead space) of Bates et al10 Anatomical dead space $(\mathrm{ml})$ was estimated from the sum of the subject's age in years and weight in pounds and added to the instrumental dead space $(70 \mathrm{ml})$. Back-pressure of $\mathrm{CO}$ in the blood was determined before and after each workload by the subject rebreathing from a bag for six breaths.

The reproducibility of the tests was assessed by considering the variability within subjects not attributable to possible systematic differences between visits. It is assumed that the within-subject variability is the same for all subjects, and it was estimated by calculating the standard deviation of the between-visit differences recorded for each subject. Expressed as a coefficient of variation, this standard deviation provides a dimensionless (inverse) measure of reproducibility, after the removal of systematic between-visit effects.

\section{Results}

Reproducibility of each lung function test between visits is shown in tables 2-4. Coefficients of variation for static lung volumes and TLCosB (table 2) are generally less than $10 \%$, except for RV and FRC in the field study.

Measurements of forced expiratory volumes and maximum expiratory airflow ( $\dot{\operatorname{Vmax}}$ ) differed in their reproducibility (table 3 ). FEV $_{1}$ and FVC were more reproducible than $\dot{V} \max _{50}$ and $\dot{V} \max _{25}$ in both groups and $\dot{\mathrm{V} m a x}$ was considerably less reproducible in the miners. FET and $\mathbf{V}$ isoV measurements were not available fiom the field

Table 2 Lung volumes and single breath transfer factor

\begin{tabular}{|c|c|c|c|c|c|c|c|}
\hline \multirow[t]{2}{*}{ Variable } & \multirow[t]{2}{*}{ No of subjects } & \multicolumn{2}{|l|}{ Visit 1} & \multicolumn{2}{|l|}{ Visit 2} & \multicolumn{2}{|c|}{ Between visits } \\
\hline & & Mean & $S D$ & Mean & $S D$ & $S D \dagger$ & $\operatorname{cov}(\%) \ddagger$ \\
\hline \multicolumn{8}{|c|}{ Laboratory } \\
\hline $\begin{array}{l}\text { FRC (1) } \\
\text { VC (1) } \\
\operatorname{RV}(1) \\
\text { TLC (1) } \\
\text { RV/TLC }(\%) \\
\text { TLCOSB* }(\mathrm{mmol} / \mathrm{min} / \mathrm{kPa})\end{array}$ & $\begin{array}{l}40 \\
40 \\
40 \\
40 \\
40 \\
40\end{array}$ & $\begin{array}{l}3 \cdot 82 \\
5 \cdot 27 \\
2 \cdot 12 \\
7 \cdot 38 \\
28 \cdot 8 \\
10 \cdot 65\end{array}$ & $\begin{array}{l}0.80 \\
0.90 \\
0.56 \\
1.00 \\
7.05 \\
1.88\end{array}$ & $\begin{array}{l}3 \cdot 71 \\
5 \cdot 20 \\
2 \cdot 06 \\
7 \cdot 26 \\
28 \cdot 3 \\
10 \cdot 69\end{array}$ & $\begin{array}{l}0.77 \\
0.82 \\
0.59 \\
0.97 \\
6.83 \\
2.06\end{array}$ & $\begin{array}{l}0 \cdot 19 \\
0 \cdot 16 \\
0 \cdot 15 \\
0 \cdot 18 \\
1 \cdot 78 \\
0 \cdot 81\end{array}$ & $\begin{array}{l}4 \cdot 9 \\
3 \cdot 1 \\
7 \cdot 3 \\
2 \cdot 4 \\
6 \cdot 2 \\
7 \cdot 5\end{array}$ \\
\hline \multicolumn{8}{|c|}{ Field } \\
\hline $\begin{array}{l}\text { FRC (1) } \\
\text { VC (1) } \\
\text { RV (1) } \\
\text { TLC (1) } \\
\text { RV/TLC (\%) } \\
\text { TLCOSB* }(\mathrm{mmol} / \mathrm{min} / \mathbf{k P a})\end{array}$ & $\begin{array}{l}38 \\
38 \\
38 \\
38 \\
38 \\
38\end{array}$ & $\begin{array}{c}3 \cdot 76 \\
5 \cdot 16 \\
2 \cdot 06 \\
7 \cdot 22 \\
28 \cdot 1 \\
10 \cdot 45\end{array}$ & $\begin{array}{r}0.94 \\
0.98 \\
0.90 \\
1 \cdot 12 \\
10 \cdot 47 \\
1.90\end{array}$ & $\begin{array}{c}3 \cdot 78 \\
5 \cdot 11 \\
2 \cdot 17 \\
7 \cdot 28 \\
29 \cdot 2 \\
10 \cdot 69\end{array}$ & $\begin{array}{r}1 \cdot 07 \\
0 \cdot 97 \\
1 \cdot 02 \\
1 \cdot 13 \\
11 \cdot 37 \\
2 \cdot 14\end{array}$ & $\begin{array}{l}0 \cdot 39 \\
0 \cdot 12 \\
0 \cdot 30 \\
0 \cdot 27 \\
2 \cdot 82 \\
0 \cdot 69\end{array}$ & $\begin{array}{r}10 \cdot 4 \\
2 \cdot 4 \\
14 \cdot 0 \\
3 \cdot 7 \\
9 \cdot 8 \\
6 \cdot 6\end{array}$ \\
\hline
\end{tabular}

* Mean of two values per subject at each visit.

+Between visits variation has been calculated after removal of any consistent visits effect.

¥Coefficient of variation: the denominator of this ratio is the grand mean. 
Table 3 Measurements of ventilatory capacity and components of the maximum expiratory flow-volume curve and closing volume

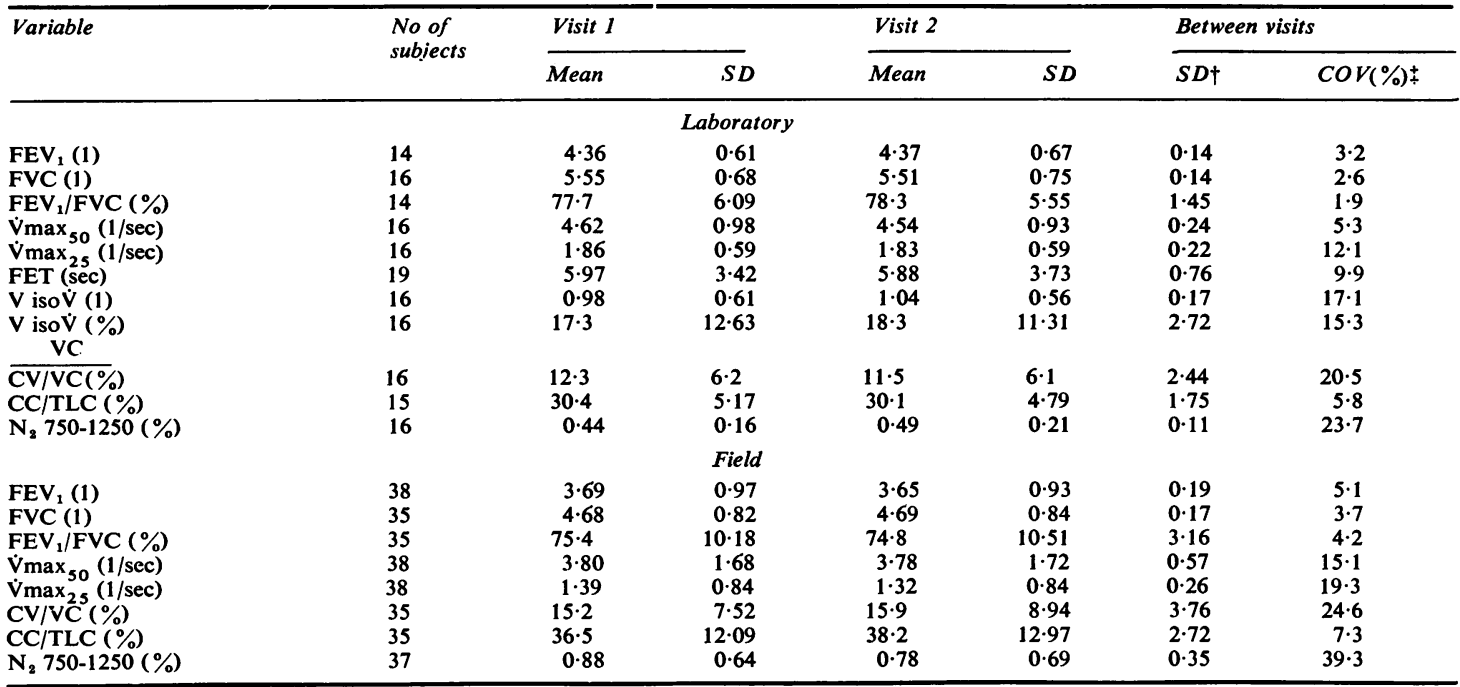

$\dagger$ See footnotes in table 2 .

Table 4 Ventilatory response to exercise and steady state transfer factor for carbon monoxide (TLcoss)

\begin{tabular}{|c|c|c|c|c|c|c|c|c|c|}
\hline \multirow[t]{2}{*}{ Variable } & \multirow{2}{*}{$\begin{array}{l}\text { Workload } \\
\text { (W) }\end{array}$} & \multicolumn{3}{|c|}{ Visit 1} & \multicolumn{3}{|c|}{ Visit 2} & \multicolumn{2}{|c|}{ Between visits } \\
\hline & & No & Mean & $S D$ & No & Mean & $S D$ & $S D+$ & $\operatorname{coV}(\%) \ddagger$ \\
\hline \multicolumn{10}{|c|}{ Laboratory } \\
\hline $\begin{array}{l}\dot{\mathrm{V}}_{\mathrm{I}}\left(1_{\mathrm{BTPS}} \mathrm{min}\right) \\
\dot{\mathrm{n}}_{\mathrm{O}_{2}}(\mathrm{mmol} / \mathrm{min}) \\
\mathrm{T}_{L} \operatorname{coss}(\mathrm{mmol} \mathrm{min} / \mathrm{kPa}) \\
\dot{\mathrm{V}}_{1} 67^{*}(1 / \mathrm{min}) \\
\mathrm{T}_{\mathrm{L}} \operatorname{co} 35^{*}(\mathrm{mmol} / \mathrm{min} / \mathrm{kPa})\end{array}$ & $\left\{\begin{array}{r}50 \\
100 \\
50 \\
100 \\
50 \\
100\end{array}\right.$ & 36 & $\begin{array}{l}24 \cdot 1 \\
37 \cdot 7 \\
39 \cdot 7 \\
61 \cdot 6 \\
12 \cdot 40 \\
16 \cdot 35 \\
40 \cdot 7 \\
15 \cdot 48\end{array}$ & $\begin{array}{l}3 \cdot 8 \\
5 \cdot 9 \\
3 \cdot 6 \\
3 \cdot 1 \\
2 \cdot 17 \\
2 \cdot 48 \\
5 \cdot 6 \\
2 \cdot 87\end{array}$ & 36 & $\begin{array}{l}23 \cdot 4 \\
37 \cdot 3 \\
38 \cdot 8 \\
60 \cdot 3 \\
12 \cdot 63 \\
16 \cdot 11 \\
42 \cdot 0 \\
15 \cdot 81\end{array}$ & $\begin{array}{l}3 \cdot 7 \\
6 \cdot 5 \\
3 \cdot 6 \\
4 \cdot 5 \\
2 \cdot 00 \\
2 \cdot 37 \\
6 \cdot 7 \\
3 \cdot 02\end{array}$ & $\begin{array}{l}1 \cdot 7 \\
3 \cdot 3 \\
2 \cdot 2 \\
2 \cdot 7 \\
1 \cdot 37 \\
1 \cdot 04 \\
2 \cdot 6 \\
0 \cdot 89\end{array}$ & $\begin{array}{r}7 \cdot 1 \\
8 \cdot 7 \\
6 \cdot 2 \\
4 \cdot 6 \\
11 \cdot 0 \\
6 \cdot 4 \\
6 \cdot 3 \\
5 \cdot 7\end{array}$ \\
\hline \multicolumn{10}{|c|}{ Field } \\
\hline $\begin{array}{l}\dot{\mathrm{V}}_{\mathrm{I}}\left(1_{\mathrm{BTPS}} \mathrm{min}\right) \\
\dot{\mathrm{n}}_{\mathrm{O} 2}(\mathrm{mmol} / \mathrm{min}) \\
\mathrm{TL} \operatorname{coss}(\mathrm{mmol} / \mathrm{min} / \mathrm{kPa}) \\
\dot{\mathrm{V}}_{\mathrm{I}} 67^{*}(1 / \mathrm{min}) \\
T_{L \operatorname{co}} 35^{*}(\mathrm{mmol} / \mathrm{min} / \mathrm{kPa})\end{array}$ & $\left\{\begin{array}{r}50 \\
100 \\
50 \\
100 \\
50 \\
100\end{array}\right.$ & $\begin{array}{l}38 \\
36 \\
38 \\
36 \\
38 \\
35 \\
37 \\
36\end{array}$ & $\begin{array}{l}24 \cdot 4 \\
37 \cdot 1 \\
39 \cdot 7 \\
62 \cdot 1 \\
14 \cdot 30 \\
15 \cdot 95 \\
41 \cdot 8 \\
16 \cdot 75\end{array}$ & $\begin{array}{l}3 \cdot 6 \\
5 \cdot 1 \\
5 \cdot 4 \\
4 \cdot 9 \\
4 \cdot 97 \\
3 \cdot 35 \\
5 \cdot 7 \\
4 \cdot 09\end{array}$ & $\begin{array}{l}36 \\
35 \\
34 \\
33 \\
33 \\
33 \\
31 \\
30\end{array}$ & $\begin{array}{l}23 \cdot 9 \\
37 \cdot 7 \\
39 \cdot 3 \\
62 \cdot 5 \\
12 \cdot 06 \\
14 \cdot 57 \\
42 \cdot 3 \\
14 \cdot 41\end{array}$ & $\begin{array}{l}3 \cdot 1 \\
5 \cdot 6 \\
4 \cdot 5 \\
4 \cdot 0 \\
2 \cdot 99 \\
2 \cdot 82 \\
5 \cdot 9 \\
3 \cdot 14\end{array}$ & $\begin{array}{l}2 \cdot 4 \\
2 \cdot 1 \\
4 \cdot 5 \\
3 \cdot 1 \\
3 \cdot 03 \\
1 \cdot 77 \\
2 \cdot 1 \\
1 \cdot 84\end{array}$ & $\begin{array}{r}10 \cdot 1 \\
5 \cdot 7 \\
11 \cdot 3 \\
4.7 \\
22.6 \\
11.6 \\
4.9 \\
11 \cdot 8\end{array}$ \\
\hline
\end{tabular}

* $\dot{\mathrm{V}}_{\mathrm{I}} 67=\dot{\mathrm{V}}_{\mathrm{I}}$ at $\dot{\mathrm{n}}_{\mathrm{O}_{2}}$ of $67 \mathrm{mmol} / \mathrm{min} ; \mathrm{TL} \operatorname{co} 35=\mathrm{TLco}$ at $\dot{\mathrm{V}}_{\mathrm{I}}$ of $35 \mathrm{l} / \mathrm{min}$. $\dagger+$ See footnotes in table 2 .

study but their coefficients of variation in the laboratory group were of the same order as those of $\dot{V} \max$.

Closing volume, as $\mathrm{CV} / \mathrm{VC}$, and the $\mathrm{N}_{2}$ index exhibited a low level of reproducibility in both groups (table 3), particularly in the miners, but expressing the results as CC/TLC considerably reduced the coefficient of variation of this measurement.

The reproducibility of measurements made during steady state exercise, at $50 \mathrm{~W}$ and $100 \mathrm{~W}$ only, is shown in table 4 to represent one mild and one moderate workload. Results from the field trial showed good reproducibility between visits for $\dot{V}_{I}$ and $\dot{n}_{\mathrm{O}_{2}}$ but a very high systematic difference between visits for TLCO, which was higher on the first visit at each workload, especially the lower ones. While the coefficient of variation of TLCO at $100 \mathrm{~W}$ was acceptably low, however, that of TLCO at $50 \mathrm{~W}$ was much higher. Reproducibility was much better in the laboratory subjects, although there was a larger systematic difference in $\dot{n}_{\mathbf{O}}$ for this group. 


\section{Discussion}

The aim of the present investigation was to establish levels of reproducibility for various tests of lung function, particularly those measured in a mobile field laboratory with inexperienced subjects. Clearly in general the index of reproducibility, the between visits coefficient of variation, was higher for measurements carried out in the field. Nevertheless, the reproducibility of many of these field measurements is acceptable when compared with those made under laboratory conditions or with values previously published.

Coefficients of variation of $1.5 \%$ for VC,11 $2 \%$ for TLC, $5.5 \%$ for RV, ${ }^{12}$ and $3.3 \%$ for FRC ${ }^{13}$ are some of the lower values available from earlier studies, confirming the generally repeatable nature of tests of static lung volume.

TLCOSB, measured on an automated spirometer system, requires several different measurements for its calculation, yet its reproducibility in our hands is good, comparing favourably with published values of about $5 \% .^{14}$

The reproducibility of $\dot{V} \max _{50}$ and $\dot{V} \max _{25}$ in our laboratory subjects confirms the findings of other workers-for example a cov of $5.4 \%$ for $\dot{V} \max _{50}$ and $9 \%$ for $\dot{V} \max _{25}$ reported by Stanescu. ${ }^{15} \mathrm{He}$ reported slightly higher values for patients with airways obstruction as other workers have done for normal subjects. ${ }^{16} 17$ There are several reasons why $\dot{V} \max$ at low lung volumes might be less reproducible than $F^{2} V_{1}$ and $F E V_{1} /$ FVC. The flow-volume curve is subject to irregular and unpredictable fluctuations; there may be different volumes expired on each occasion; the subject's effort may vary and our use of the mean of three, rather than the maximum, values may increase the apparent within individual variability. These factors may well be of greater significance in the group studied in the field.

The recent reintroduction of FET as a screening test of lung function prompted us to examine its repeatability. Its usefulness has been questioned because of a high degree of variability within subjects: coefficients of $13 \%{ }^{16}$ and $21-26 \%{ }^{18}$ have been reported. Our results were more reproducible than these, possibly because of different methods of measurement. Previous workers have measured FET from a volume/time spirometric trace or by using the stop-watch/stethoscope method. Our method, which relies on a timing system de-activated by a threshold flow device, tends by its nature and in practice to give rise to rather longer expiratory times than published values even in normal subjects (typically 4-6 seconds). These were repeatable in a given subject however, although some of the longer times found in older men may have been related to lack of motivation as much as to abnormalities in airways.

On the other hand, the volume of isoflow ( $\mathrm{V}$ iso $\dot{V}$ ) is in principle likely to be more difficult to replicate successfully on different occasions in the same subject. Estimation of the isoflow point on the flowvolume curve may be influenced by test to test differences in (1) inspiratory VC; (2) expiratory VC; (3) level of maximum expiratory flow on air or $\mathrm{He} / \mathrm{O}_{2}$ curves; (4) subjective assessment by the observer of the point of isoflow, which may in turn depend on the technique used for recording and the physical size of the recording icale; and (5) distribution of helium during the preceding three VC breaths and subsequent washout between tests, particularly in those with expiratory airflow limitation. Possibly because of some of the above factors the reproducibility of $\mathrm{V}$ iso $\dot{V}$ has been found to be poor. Sudlow et al ${ }^{19}$ observed wide variation of $\mathrm{V}$ iso $\mathrm{V} / \mathrm{VC}$ ( $\mathrm{cov}=60.8 \%$ ) in five repetitions of this measurement carried out over a period of six months in a group of healthy non-smokers experienced in performing lung function tests. which was considerably greater than the variation reported here. Its usefulness as a sensitive discriminatory test of lung function in apparently healthy smokers. however, has previously been reported. 520

The large variability of duplicate determinations of $\mathrm{CV} / \mathrm{VC}$ in both laboratory and field populations confirms the findings of other workers. ${ }^{2} 3$ The reduction in the coefficient of variation but not the $\mathrm{SD}$, when the results were expressed as CC/TLC $(=(C V+R V) /(V C+R V))$, is due to the relatively greater increase in the numerator causing an increased absolute mean value with no increase in the SD of the between-visit measurement, again confirming the findings of Becklake $e t$ al.$^{2}$ There can be genuine differences, however, between determinations of the point at which inflection occurs. CV may be influenced by incomplete filling or emptying of the lungs and by daily variations in VC, which may not be related to the former, although it appears not to depend on diurnal rhythms nor to be amenable to training. ${ }^{3}$ We may have underestimated the variation of CC/TLC, since single estimations of RV (by helium dilution) were used.

The coefficient of variation of the $\mathrm{N}_{2}$ index was unusually large. One reason for this was the difficulty of reading accurately on the recording paper alterations of about $1 \mathrm{~mm}$ (representing $0.5 \% \mathrm{~N}_{2}$ ). When related to the average normal value of $0.5-1.0 \%$ (that is $1-2 \mathrm{~mm}$ on the record) small errors in reading these alterations would produce large covs. In abnormal states, however, the value of this index may increase by two-to ten-fold and hence 
tends to eliminate this difficulty. The larger coefficient of variation in our field study is unsatisfactory and compares unfavourably with the laboratory results and other published values. For example, McCarthy et al ${ }^{21}$ found that the cov for each of 20 subjects studied weekly for 10 weeks was about $20 \%$.

Ventilatory response to exercise was found to be a very reproducible test, although less so at the lowest workload in the miners. The small systematic error in n ${ }^{\circ} 2$ of the laboratory subjects may have been due to some undetected instrumental fault, because omission of five subjects on one day and reanalysis (not shown in table 4) eliminated the systematic difference at all but the highest workloads.

Reproducibility of TLCoss between visits has not been reported before, but Holmgren, ${ }^{22}$ who used arterial blood analyses to calculate physiological dead space, has reported a cov of $7.2 \%$ in duplicate determinations made on the same day. Holmgren's analysis, which differed slightly from our own, might have yielded a similar cov if conducted on measurements made on separate days, but one would expect his within-day cov to be less than our between-day cov. The repeatability of this test in both groups was generally good at the higher workloads but there was a large systematic difference in the miners. This difference is difficult to explain completely, since it appears to be unrelated to hyperventilation on eithur occasion, or to differences in ventilation, inspired gas concentrations, technicians, or environmental factors.

As pointed out by West, ${ }^{23}$ however, the method of calculation of TLco used here, which is based on an assumed dead space/tidal volume ratio and a measured $\mathrm{CO}$ extraction, is apt to cause an overestimation of TLCo when the ratio is high-for example, during low workloads or when $\mathrm{CO}$ extraction is high, as in a fit young man. A combination of these factors will give rise to an artificially high TLco especially at low workloads. It was found that estimation of TLCo at a workload of $100 \mathrm{~W}$ provided the most reproducible results and would probably be our method of choice if a single estimation were to be made during exercise.

The finding that most measurements were generally less reproducible in the field study of coalminers is not unexpected in view of the subjects' lack of familiarity with the apparatus and the operators. Caution should therefore be exercised in applying levels of reproducibility which have been derived from "trained" subjects in the laboratory to a group of the general population or to industrial workers. Although the more recently introduced tests, FET and $V$ iso $\dot{V}$, were not examined for their repeatability in the mobile laboratory, it is en- couraging that these tests exhibited better reproducibility than was indicated by previous reports.

Detels et $a l^{24}$ also measured lung function in a laboratory by means of spirometry, single breath oxygen test, and body plethysmography. Measurements on their 94 adult subjects were repeated later in a pulmonary function laboratory. They reached broadly similar conclusions regarding the repeatability of these tests.

The conventional index of reproducibility discussed above (cov) is convenient for comparing different tests because it is dimensionless. It is not to be regarded, however, as the sole criterion when considering tests for possible use in epidemiological surveys. The ability of a test to discriminate between groups is a function not only of its reproducibility in indiviauals but also of the scatter within groups and of the numbers of individuals in each group. If costs allow the numbers examined may be increased at will. However, the specificity of a test to the physiological feature of interest is equally important. Whether or not a "specific test of small airways function" with poor reproducibility is to be preferred to a non-specific but highly repeatable test such as $\mathrm{FEV}_{1}$ will be determined by their continued use in long-term follow-up studies of lung function in groups of closely monitored industrial workers.

We thank Mr J Birkett, Miss E Donaldson, Mr K Sweetland, and Mr TD Wilson for their technical help, Mrs MG Garden for typing the manuscript, and all the miners and other volunteers who took part in this study.

\section{References}

${ }^{1}$ Rogan JM, Attfield MD, Jacobsen M, Rae S, Walker DD, Walton WH. Role of dust in the working environment in development of chronic bronchitis in British coal miners. Br J Ind Med 1973;30:217-26.

${ }^{2}$ Becklake MR, Leclerc M, Strobach H, Swift J. The $\mathrm{N}_{2}$ closing volume test in population studies. Sources of variation and reproducibility. $A m$ Rev Respir Dis $1975 ; 111: 141-7$.

${ }^{3}$ McFadden ER Jr, Holmes B, Kiker R. Variability of closing volume measurements in normal man. Am Rev Respir Dis 1975;111:135-40.

${ }^{4}$ Meade F, Saunders MJ, Hyett F, Reynolds JA, Pearl N, Cotes JE. Automatic measurement of lung function. Lancet 1965;2:573-5.

${ }_{5}^{5}$ Hutcheon M, Griffin P, Levison H, Zamel N. Volume of isoflow: a new test in detection of mild abnormalities of lung mechanics. Am Rev Respir Dis 1974;110:458-65.

${ }^{6}$ Fowler WS. Lung function studies III. Uneven pulmonary ventilation in normal subjects and in patients with pulmonary disease. J Appl Physiol 1949;2:283-99.

7 Anthonisen NR. Dawson J, Robertson PC, Ross WRD. Airway closure as a function of age. Respir Physiol 1970;8:58-65.

${ }^{8}$ Leblanc P, Ruff F, Milic-Emili J. Effects of age and body 
position on "airway closure" in man. $J$ Appl Physiol $1970 ; 28: 448-51$.

${ }^{9}$ Division of Lung Diseases. Suggested standardised procedures for closing volume determinations (nitrogen method). USA: National Heart and Lung Institute 1973.

${ }^{10}$ Bates DV, Boucot NG, Dormer AE. The pulmonary diffusing capacity in normal subjects. $J$ Physiol 1955; 129:237-52.

${ }^{11}$ Gilson JC, Hugh-Jones P. The measurement of the total lung volume and breathing capacity. Cl Sci 1949;7: 185-216.

${ }^{12}$ Rahn H, Fenn WP, Otis AB. Daily variations of vital capacity, residual air and expiratory reserve including a study of the residual air method. J Appl Physiol 1949; $1: 725-36$.

13 Needham CD, Rogan MD, McDonald I. Normal standards for lung volumes, intrapulmonary gas mixing and maximum breathing capacity. Thorax 1954;9:313-25.

14 Cotes JE. Respiratory function tests in pneumoconioses. Geneva: International Labour Office, 1966:93.

${ }^{15}$ Stanescu DC. Early detection of chronic bronchitis and emphysema. Rev Inst Hyg Mines 1975;30:3-51.

${ }^{16}$ Cochrane GM, Prieto F, Clark TJH. Intrasubject variability of maximal expiratory flow-volume curve. Thorax 1977;32:171-6.
17 Green M, Mead J, Turner JM. Variability of maximum expiratory flow-volume curves. J Appl Physiol 1974; 37:67-74.

${ }_{18}$ Macdonald JB, Cole TJ, Seaton A. Forced expiratory time-its reliability as a lung function test. Thorax 1975;30:554-9.

${ }^{19}$ Sudlow MF, Costello JF, Flenley DC. Millar J. Reproducibility and correlation of tests of "small airways disease." Bull Eur Physiopathol Respir 1975;11:16P-20P.

20 Gelb AF, Molony PA, Klein E, Aronstam PS. Sensitivity of volume of isoflow in the detection of mild airway obstruction. Am Rev Respir Dis 1975;112:401-5.

${ }^{21}$ McCarthy DS, Craig DB, Cherniack RM. Intraindividual variability in maximal expiratory flowvolume and closing volume in asymptomatic subjects. Am Rev Respir Dis 1975;112:407-11.

${ }^{22}$ Holmgren A. On the reproducibility of steady state DLCo measurements during exercise in men. Scand J Clin Lab Invest $1965 ; 17: 110-6$.

${ }^{23}$ West JB. Diffusing capacity of the lung for carbon monoxide at high altitude. J Appl Physiol 1962;17:421-6.

${ }^{24}$ Detels R, Coulson A, Tashkin D, Rokaw S. Reliability of plethysmography, the single breath oxygen test and spirometry in population studies. Bull Eur Physiopathol Respir 1975;11:9-30. 